\title{
Call for Papers \\ IEEJ Journal of Industry Applications \\ Special Issue on “JIASC2018"
}

Program Committee, Industry Applications Society

Technical Program Committee, JIASC2018

The Industry Applications Society of the Institute of Electrical Engineers of Japan (IEEJ) plans to publish a special issue of the IEEJ Journal of Industry Applications for 2018 IEE-Japan Industry Applications Society Conference (JIASC2018) in May 2019. Papers are invited on any aspect of the principles, theory and engineering methodologies for industry applications.

Please note that papers that have not been presented at JIASC2018 will not be considered for inclusion in the special issue.

\section{IMPORTANT IMFORMATION}

Special Issue:

IEEJ Journal of Industry Applications, Vol. 8, No.4, 2019

Paper submission dead line:

June 30, 2018

Submission Web site:

https://submit.iee.or.jp/main/cgi/sstk-top.cgi?lang=E

\section{IMPORTANT NOTICE}

1. IEEJ publishes several different Transactions. Thus, please be sure to submit your paper from IEEJ Journal of Industry Applications (English only). In addition, please select the theme of a special issue on "JIASC2018". Important Notice: JIASC2018 Submitted Paper [6 pages] Only

2. The submitted papers will be reviewed based on the Author's Guidelines for IEEJ.

URL: http://www.iee.jp/?page_id=5975

3. Note that the manuscript will not be included in the Special Issues, if the manuscript is not accepted for publication by the deadline for the Special Issue as a consequence of revisions requested by referees.

4. The authors (or their institution) are requested to pay publication charge. See for details in the Author's Guidelines.

5. Papers should be submitted on the web-based system. For online submission, authors are requested to register as a user.

\section{CONTACTS}

Prof. Nobukazu Hoshi, Tokyo University of Science

Guest Editor, Special Issue on JIASC2018

E-mail: nhoshi(at)rs.noda.tus.ac.jp 